\title{
The current status of new health care reform
}

\author{
Jinguo Wang ${ }^{1, \mathrm{a}}$ and $\mathrm{Na}$ Wang $^{2, \mathrm{~b}^{*}}$ \\ ${ }^{1}$ the First Hospital of Jilin University, Changchun 130021, China; \\ 2 the First Hospital of Jilin University, Changchun 130021, China \\ awangjinguolily@163.com, bwangna080613@163.com
}

Keywords: System construction, health care, reform.

\begin{abstract}
In the new health care plan pay more attention to improving the security of medical and health undertakings, first of all, establish a strict and effective medicine and health care regulation system, speed up the construction of the medical and health personnel, focus on strengthening the public health, rural health and urban community health and nursing personnel training, professional and technical personnel to strengthen the system of continuing medical education. Finally, countries to speed up the adjustment of higher medical education structure and scale and expand the investment in urban and rural medical institutions, for the treatment of patients with high security protection.
\end{abstract}

\section{Introduction}

From at the beginning of the founding of new China to now, China both in economic construction and social face great changes have taken place, including medical and health system reform caused by the change.Along with the country prosperous and social progress, people's livelihood problems become more and more attention by government and society, medical and health undertakings, as one of the important content of society and people's livelihood project, it not only relationship sword common people's life and health, is also the basis of the foundation of the national development and social stability.

\section{Text}

In the past 30 years, under the condition of market economy of China's medical and health system reform, great changes have taken place in medical and health undertakings made a certain progress in some aspects. However, the current health care system there is still a serious problem, far cannot satisfy the masses of the people for the increasing needs of the medical health service. The first question (or the focus of the whole society the most), medical costs rose more than ordinary income growth, resulting in people "expensive". A lot of people sick because of the economic difficulties cannot be healed. More seriously, the ordinary outpatient medical expenses are rising fastest, resulting in a large number of feel sick people because no money and not to go to the clinic. Medical and health resources relative shortage, lead to the medical service supply, people to see the doctor is not on the team, hospital beds, resulting in people "medical care". The main reason is because of China's medical and health resources allocation has long been a "nabla" state, $80 \%$ of the medical and health resources is concentrated in cities, $80 \%$ of urban medical and health resources are concentrated in large hospitals, and rural and community health service resources relative lack [1]. Therefore, the government in order to accelerate the reform of new round of medical and health system, in order to solve the difficulty and high cost of the people "see a doctor", become the key of the construction of a harmonious socialist society.

Since July 2005, the China youth daily in order to "health research institution under the state council report says China is not successful", submitted to the state council development research center, the main content of the research on medical and health system reform in our country. The latest round of medical and health system reform began. In June 2006, the state council executive meeting, decided to carry out the work we will deepen reform of the medical and health system. $n$ August, the state council is deepening the reform of medical health system inter-ministerial 
coordination group, by the national development and reform commission, the ministry of health, ministry of finance and other 16 departments to participate in the health care team. Health care team through focus group research, focuses on the key and difficult problem in the field of Chinese medical and health care [2]. Write a research report, then by Peking University, the state council development research center, the world bank, the social security research center, Beijing normal university, Wuhan university, fudan university, the world health organization (who), McKinsey, renmin university of China has nine organizations respectively to the national medical and health system reform inter-ministerial coordination group presented a reform proposal, for China's health system reform put forward the principle and system design framework. This is the nine of China's new medical reform plan, is the cornerstone of China's new healthcare reform. Finally, after more than two years by the health care team, and finally formed the "about the opinions of the deepening medical and health system reform" (referred to as "the new healthcare reform") submitted to the state council. At this point, a new round of reform China formally opened the curtain. However, because of the complexity of the reform itself and progressive, concrete plans will not in office.T he opinions were put forward "a system of target, the big four, eight supporting framework of the overall reform." Because, the relevant functional departments of a new round of reform of some key issues have different views, so, a new round of healthcare reform on some major issues just put forward the principle of guidance, the concrete plan to develop, only by supporting and flexible by local according to local actual situation.

Now domestic expert opinions and Suggestions of China's new health care model for very much, I will be published on representative generalization, according to the reform ideas tend to be as long as it is dependent on the government will have to rely on market forces set is divided into the government leading and market leading, advocate at the same time use of government and market effect is classified as moderate [3]. Government-led sent supporters think the marketization of medical and health system reform in China, commercial mode, contrary to the basic law of the development of medical and health undertakings, the reform of the main idea is to strengthen the government responsibility, increasing investment and strengthening the regulation and the transformation government function, and the medical and health services is divided into public health and basic medical and health services and basic medical service three levels: the public health service has the government provided free of charge to all the social members. Basic medical and health services of government investment is given priority to, in view of the most common disease, frequently-occurring disease, to provide the needed drugs and diagnostic methods of basic medical service pack. Non basic medical service by the residents themselves take responsibility. Market leading to send the main, supporters say, is the main train of thought of reform bureaucracy left hospital management, protection of rights and interests of all involved in the equality of competitors, and introduction of match the rights and interests increase the magnitude of the punishment reinforcement mechanism, establish medical cost audit committee, regularly publish medical price. And moderate reform train of thought should be reduced

Low information rent and the risk of moral hazard is the key to the healthy development of the medical and health services industry, under the effective supervision, to promote commercial insurance institutions play a unique advantage, explore a public-private partnerships, public sector and private sector to establish a long-term partnership, through the agreement to establish this relationship, and accept the supervision and administration in accordance with the government [5]. The author believes that the views of two major factions, each has its own advantages and disadvantages, simply use one of the health reform mode is not desirable, because the whole of China 60 years of reform experience and lesson tells us, want to combine China's national conditions, explore a accord with the actual situation of China and reform path with Chinese characteristics is the key to success.

At present, China has kicked off the new health care reform, summarizes the failure of the previous experience, stick to ethical prior to the development of economy and science. Firmly grasp the moral is the driving force for the social progress, the socialist market economy is moral economy, China's medical and health system reform is not only an economic problem, but it is also a moral 
problem, moral as the economic operation of intangible assets, is particularly important. The antinomy phenomenon is objective existence in China. Mainly embodied in the rapid economic development and moral construction lag, the antinomy of the economy and ethics is not absolute, but relatively, when society requires to be priority to the development of economy and science and technology, tend to ignore the pace of the construction of the ethics, and when the economy and the development of science and technology to a certain extent, the ethics construction will take precedence over the development of economy and science and technology. From the historical process of China's reform of medical and health care system, medical and health system reform and the ethical relationship "is one against one" of the process of negation of negation. But this antinomy is not eternal, the commutation position according to the actual needs. So, China's new health care reform has ever unique connotation, the characteristics of the embodied in the following four aspects.

Medical fairness is the first ethical concept. China's new health care reform in the success of the decisive factors or in the government should play a leading .Before the reform of China's medical and health care in the government to give priority to. Health care resources and the distribution of different groups in different health field is unified by the government planning, organization and management and according to the strict plan implementation by the government. To ensure that the vast majority of citizens are able to get the most basic medical and health services and improve the national health level.

After the reform of China's medical and health system reform basically is not successful. And the creation of China's new healthcare reform, is the national medical health system reform at the invitation of inter-ministerial coordination group by nine institutions at home and abroad to submit a separate package. Throughout nine sets of design scheme of China's new health care reform, each scheme respectively from the establishment and perfection of the universal health care system, the role of public finance in health financing, medical and health care payment mechanism reform, the reform of medical and health service system, medical and health care administration and reform of the regulatory system and the reform of the system of drug that six aspects for advices. Through the government's unified plan, organize and vigorously inputs, universal health care system to be more perfect. The government to increase health care spending, finance minister xie xuren put forward "in 2009 after three years to carry out the five key reform work, governments at various levels should be new investment 850 billion yuan, of which the central government should be the new finance $33 \$ 1$, 800 million." Rely on social organizations to supervision and management of China's medical and health cause, ensure the smooth progress of China's new medical reform. The basic drug system preliminary established. And issued the national list of essential medicines (2009 edition), to ensure the safety of production supply and quality of essential drugs, reasonable to determine the price of basic drugs, the public bidding procurement and direct distribution, promote the rational use of basic drugs, improve the basic medical insurance reimbursement ratio, ease the burden of basic drugs. Medical and health care billing system more human, scientific. Medical and health service system has been the rapid development, has formed, including medical treatment, disease prevention, health care, rehabilitation, such as teaching, scientific research, relatively complete, reasonable layout of medical and health system. Among them, the rural integrating prevention, health care and treatment of three-level medical service in a body building and effective especially deserves praise. Gradually develop and improve the system, improve the accessibility of services, and basically settled the problem of urban and rural areas, especially rural underserved, highlighted the medical fair priority ethics idea [4].

Medical and health work the intervention of the key to reasonable choice. The government should provide citizens with a moderate amount of health care protection of labor resources and the improvement of social justice and social welfare. According to the government fiscal capacity and efficiency, at the same time of protecting labor resources, for the treatment of common diseases and has high value of diseases to provide a certain degree of compensation, achieve the goal of improving social welfare. The ministry of human resources and social security minister Yin weimin proposed "in 2009, the residents around to worker health, health is the highest pay limitation to local worker year of average wage and residents' disposable income about 6 times. To gradually increase the 
proportion of pay for inpatient and outpatient service a serious illness, worker health care this year and the proportion of residents' health care in hospital medical expenses to common reached $70 \%$ and $50 \%$ above conditional region, to start from a lower level, common disease, frequently-occurring disease outpatient medical expenses will be incorporated into the medical insurance to pay limits." Minister of health Chen zhu "is put forward to raise the level of basic medical insurance, governments at various levels in 2010 to the allowances for urban residents in health care and new farming raised to 120 yuan per person per year, and appropriately increase individual pay cost standard. Gradually increase the policy within the scope of the hospitalization expenses proportion and highest pay limitation, gradually expanding the scope of the outpatient expenses and proportion." The author thinks that, in view of the intervention on medical and health work, in addition to improve the medical expenses of allowances, to highlight the "prevention first" and attaches great importance to the development of public health, into public health priority. Medical technical route choice also should notice to appropriate technologies, emphasizes the combination of Chinese and western medicine. In addition, the government's standards, norms of medical service and so on also should have more strict control, to standardize medical service behavior, both doctors keep a good harmony and interaction, prominent in the public medical and health care, prevention, health care benefits first ethical concepts.

\section{Summary}

In short, China's new health care compared with the above mentioned two stages, the new medical reform has made breakthrough progress, and have the characteristics of the new period.But any healthcare reform policy, the promulgation and implementation measures have a certain time lag, which leads to the emergence of many problems. The author through careful insight into the progress of China's new health care reform, and found that there are still many problems unresolved, it mainly includes the problem of responsibility of the government, medical and health institutions of public welfare, medical and health resources allocation fairness problem, the problem of medical and health security system and pharmaceutical producing circulation problems and so on many facets, and in this paper, the author only had three key problems about the analysis, then to conduct the thorough research to the existing problems of China's new medical reform.

\section{References}

[1] Lujun Gao, Ling Liu, Jihui Zhang, Lidan Hou. Building of Smart Home Medical System Based on Internet of Things [A]. Proceedings of 2016 Cloud Computing and Internet of Things Conference (CCIOTC2016) [C]. 2016

[2] Xianxiang Chen, Zhen Fang, Ren Ren, Shanhong Xia, Yangmin Qian, Huaiyong Li, Lili Tian, Wenxi Zhai, Weibing Xu, Hui Gao. Simple and efficient baseline removal method for a smartphone based ECG detection device [A]. Proceedings of 2013 International Conference on Future Computer and Information Technology (ICFCIT 2013) [C]. 2013

[3] Fang Qingwei. Research on Evaluation Index System of Management Effectiveness on Hospital Human Resource Based on Balanced Scorecard [A]. Proceedings of 2011 International Conference on Fuzzy Systems and Neural Computing (FSNC 2011 V2) [C]. 2011

[4] Thepparit Sinthamrongruk, Napat Harnpomchai. Determination of optimal number of doctors and appointment interval for an appointment [A]. Proceedings of the International Conference on Information Engineering and Education Science [C]. 2014 